\title{
Thinking with Things: Landscapes, Connections and Performances as Modes of Building Shared Understanding
}

\author{
D. Lockton, L. Forlano, J. Fass, and L. Brawley
}

\begin{abstract}
This article explores the relatively underexplored potential for physicalisations to materialise qualitative data related to human experiences and knowledge domains. Our reading of 'data' in this context extends from imperceptible systems and infrastructures to mental models and the phenomenological dimensions of experiences themselves. Physical objects can be regarded as a form of knowledge with which to inquire about human life, bring about improved conditions, and imagine alternative realities. Objects are made of materials, which are manipulated materials into various configurations. The materials used in the process of externalisation have a profound influence on the resulting forms, and through them on how knowledge is constructed and internalised. We pay detailed attention to the characteristics of materials and how they are combined, in the context of interdisciplinary exchange. We are motivated by the need for a shared understanding of what work materials can do in the making of physicalisations. We suggest this work is useful in the analysis of physicalisations, specifically where they seek to articulate the phenomena of lived experience.
\end{abstract}

Index Terms - Boundary representations, Design Tools and Techniques, Elicitation methods, Knowledge sharing, Physically based modeling

\section{INTRODUCTION}

THIS essay explores "thinking with things" at the intersection of generative co-design and data physicalization. This article and our work take a view of data physicalization that goes beyond the expression of a specific quantitative data set in physical form. Instead, as designers what we mean by data is closer to what is generated in design practice, more specifically, in generative co-design situations. We are interested in the relationship between what people can imagine, what materials are available to them, and what types of what kinds of shared understanding emerge. We have applied this thinking to many different topics, including emotional response, social networks, and most recently how we might help people express their feelings and attitudes to the systems they inhabit. By experience we mean to explore the phenomenological nature of everyday life; for example, how people think about their relationships to technology, how people understand their own personal and professional trajectories; and how these shape their understanding of disciplinary boundaries. This

- Dan Lockton is with the Imaginaries Lab, College of Fine Arts, Carnegie Mellon University, Pittsburgh, PA 15213. E-mail: danlockton@cmu.edu.

- Laura Forlano is with the Institute of Design, Illinois Institute of Technology, Chicago, IL 60616. E-mail lforlano@id.iit.edu.

- John Fass leads the MA User Experience Design Program at London College of Communication, London SE1 6SB E-mail: j.fass@arts.ac.uk

- Lisa Brawley teaches in the Urban Studies Program at Vassar College, Poughkeepsie, NY 12604. E-mail: lbrawley@vassar.edu.

Brawley, Fass, Forlano, and Lockton contributed equally to this work. John Fass corresponding author: j.fass@arts.ac.uk work has taken on importance as the intersection of complex socio-technical systems comes to dominate human experience, and the way those systems are regulated and arranged becomes ever more opaque. We seek to access these types of knowledge by giving people the opportunity to express them in physical form.

Tversky[1] suggests that "when thought overwhelms the mind, the mind puts it into the world," noting how "people use anything at hand, their hands, their bodies, arrangements of sticks and stones and coffee cups, sketches in the sand, scribbles on paper napkins, and more" as "external representations of thought...designed to serve thought, for self or for others". While the use of drawing in this context has been relatively widely explored, physical models have been less so.

In design fields like architecture, planning and product design, physical models can narrow the gap (and the glitches) between abstract concepts and concrete implementation by allowing complexities to surface as part of the design process. Physical models are often used to surface implicit assumptions and values as well as to communicate and test ideas; they are especially useful tools for working with the qualitative, experiential elements of a design, i.e. the quality of the lighting, the effect of an acoustic environment, the feel of the surface of an object. Physical models allow for the development of new guiding metaphors, which can be a critical way for designers to generate and communicate their internal understandings. They also enable a public to convey their experience of a design- 
concept in process in order to more meaningfully inform a design. Kirsh[2] finds that 'the materiality of external representations provides affordances that internal representations lack.' We are interested in what these affordances may be and how participants in co-design activities have taken advantage of them. More specially, we are interested in what materials one might use to physicalize the qualitative data that is generated and enabled in any design or codesign process. How do materials matter?

To explore these points, we use examples of our work drawn from a half-day co-design workshop held in the context of the Relating Systems Thinking and Design conference in Chicago in 2019. The methodological focus of our workshop was on "Tangible Thinking." The thematic focus was on how participants conceptualize and experience "disciplinarity and interdisciplinarity" - abstract ideas that regulate and structure the lives of participants in a professional conference. We explored three different ways of making ideas tangible-topological, connective and performative-as described below.

\section{BACKGROUND}

In the field of science and technology studies (STS), many social scientists have studied the ways in which scientists visualize and model their data, creating images and objects that allow for the development of new ideas and knowledge. This has led to a wide variety of concepts such as epistemic things[3], epistemic objects[4], conscription devices and boundary objects[5]. One of the features of these things, devices, and objects is that they foster multiple people to engage with an idea at the same time. In addition, they can be useful, as in the case with boundary objects, for fostering interdisciplinary conversations. A related concept, that of 'trading zones' is also useful for understanding the ways in which interdisciplinary knowledge can be shared, and, even, for the formation of new fields of knowledge[6]. The idea here is that for new areas of knowledge to emerge, they must first develop pidgin languages and dialects that cross the existing fields.

In what are known as 'inventive methods'[7] as part of the post-critical turn, scholars in a range of fields are themselves exploring the use of visual and physical forms of knowledge-making through practice-based research, design as inquiry, and research creation[8]. For example, scholars in the humanities have engaged with experimentation and objects through what Sayers calls conceptual matter.[9] This has led to a wide range of critical making[10], critical data practices, critical technological praxis and critical media practices.

Some of these concepts have already been adopted in the field of design. For example, building on the concept of boundary objects and cultural probes, Halpern, Erickson, Forlano and Gay developed the concept of boundary probes based on a co-design workshop activity[11]. Designers have been interested both in the discursive potential of prototypes, as well as their speculative potential, which Wakkary et al. refer to as material speculation.[12] A related concept, provotypes[13] (provocative prototypes), draws productively on the tension between stakeholders for the purpose of participatory innovation. Finally, speculative design, design fiction and experiential futures have also made use of objects for promoting critical thinking about our present conditions as well as alternative possible futures. There are parallels with emergent themes in data physicalization, such as constructive visualization and personal physicalization constructions for self-reflection.

As social scientists, urbanist, design researchers and designers, we have used the affordances of physical objects in our previous projects about the future of work autonomous vehicles, and digital social networks. In bringing our interests to the analyses of socio-technical systems, we have observed that many diagrams focus on depicting the links in networks but very little has been done to illustrate the quality of relations in the models. How might different theories about the social be prototyped and embedded in physical models? For example, in sociology, theories about the strength of weak ties, could be integrated into physical models.

In the words of Haraway, "It matters what matters we use to think other matters with; it matters what stories we tell to tell other stories with; it matters what knots knot knots, what thoughts think thoughts, what ties tie ties. It matters what stories make worlds, what worlds make stories," [14] So, 'matters' matter, but does matter also matter? And, if so, in what ways does it matter? Furthermore, what kinds of matter support what kind of thinking and how does their materiality matter?

\section{THE WORKSHOP}

Our article seeks to explore these questions based on a workshop that we ran at RSD 8 in Chicago in Fall 2019. The workshop was attended by designers, students, systems theorists, and academics from varying disciplinary locations within higher education and from differing areas of practice in the design industry. Most of the participants did not know one another. The workshop took four hours: it featured a brief orientation and context-setting session, followed by three one-hour sessions each of which explored a different modes of physicalizing ideas: landscape, connection, dynamics. Participants worked in small groups of five to eight people to co-design models in response to questions posed about how they understood and experienced disciplinarity and interdisciplinarity. At the close of each session, groups shared their models drawing on the narrative that co-creating the model had generated. The workshop involved groups of people working collaboratively on a common creative task. Drawing on the tradition of co-design, we emphasized the generative nature of the exercise and the value of shared experience. Our use of richly varied materials is in sharp contrast to the stifling conformity of co-design methods and their walls of post it notes. The workshop emphasized a co-created expressive activity designed to enable the surfacing of latent or otherwise unexpressed awareness that enhances a discussion at group level. We describe each of the three sessions and their differing material strategies below. 


\subsection{Deploying Elements of Landscape}

In the first session, participants worked with a pre-designed kit of parts that featured elements of landscape, the Mental Landscapes kit[15] (Figure 1, Figure 2). This kit comprises a selection of laser-cut card elements acting as "visual prostheses"[16], embodying a particular set of metaphors based around stylized landscapes and features within landscapes, such as hills, roads, bridges, fields, fences, and weather. These include: hills, mountains, and raised ground, of many sizes and colors-both 3D cones and flat elevations held vertically using slotted blocks; lakes, ponds, and rivers, of many sizes and colors, plus 'whirlpools' or eddies; fields / areas of land, of many sizes and colors, including a 'ground' sheet; roads, bridges, and fences which could also be interpreted as railway tracks; trees and cacti of different shapes and sizes; silhouettes of people of different sizes; weather elements such as sun/moon, clouds (cirrus-esque and cumulus-esque), clouds with rain, clouds with snow, clouds with lightning bolts, held vertically using crocodile clips on rods (whirlpools could also be used as 'cyclones'); sticky notes for use as labels or annotations; and generic shapes, modifiable in different ways. The main material affordances involve the flexibility of-and ability to write on-the card elements (figure 2); in addition, the variety of easily (re)positionable lightweight elements is a significant property, inviting particular forms of interaction and configuration. Participants can also modify the card elements by cutting them and joining them together, and-although it can probably go without saying - creative reinterpretations of what particular elements represent, or could be metaphors for, are strongly encouraged. Our design process aimed to maximize participants' ability to express their thinking, while not overwhelming them with sheer quantity of pre-made elements. We wanted to provide opportunities for expression without prescribing a particular narrative format, although 'journeys' of various kinds have often resulted.

The Mental Landscapes kit has been used in workshops where participants assemble and arrange a variety of elements to make abstracted model landscapes which on some level represent or translate their mental models of concepts, experiences, or relations between ideas. Through a series of workshops in both academic and non-academic settings, participants have built models representing their own career paths, life journeys, group projects, how they feel within their workplace culture, and visions of humanity's past and future. Some activities have been individual, while others are group-based to try to examine the collective imaginaries of a particular theme or idea. Aside from gaining insights around the topics being explored-acting as a form of probe-the primary aim of the workshops at this stage has been to help scope possibilities for the kit's development and to explore how this kind of metaphorbased physicalization method could be used in user research, in higher education classrooms, and, perhaps, even in art therapy.

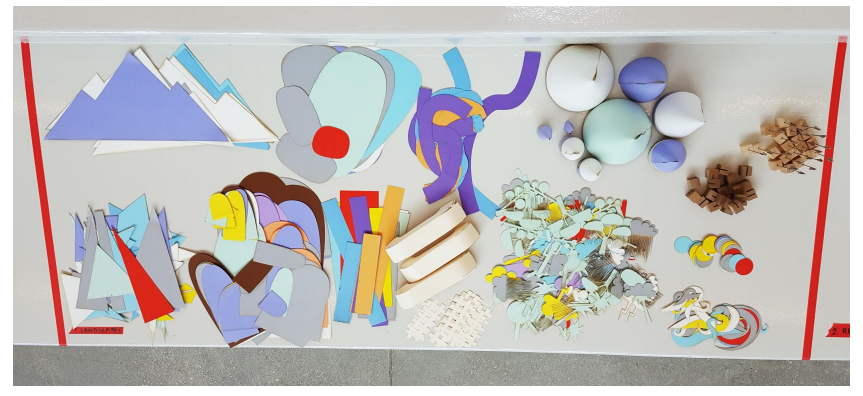

Figure 1. Elements of the Mental Landscapes kit laid out for participants. Image: Dan Lockton.

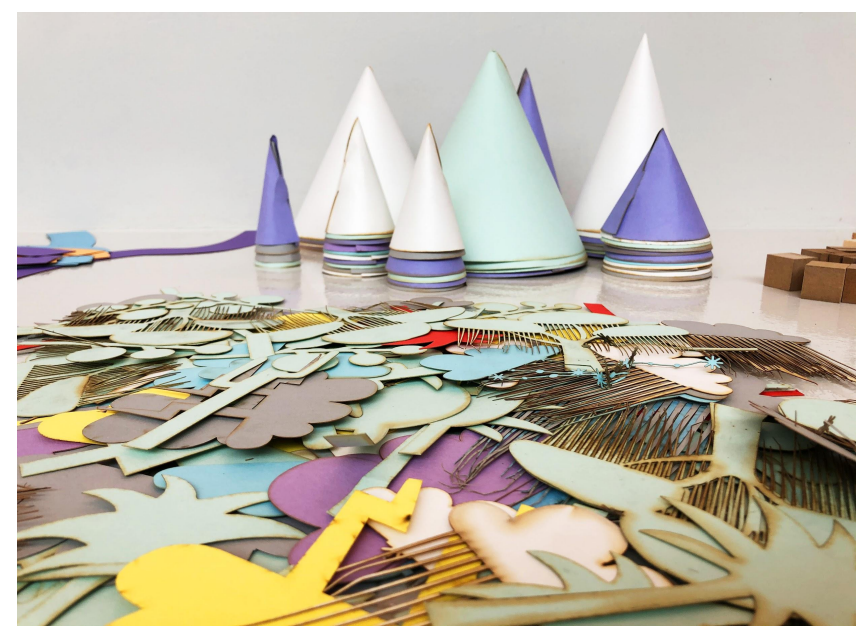

Figure 2. Elements of the Mental Landscapes kit laid out for participants to choose from. The wooden blocks are used to enable flat elements to be held vertically. Image: Manuela Aguirre Ulloa.

Landscapes are a common type of metaphor in speech, particularly for talking about relations between parts of a whole, or mapping the structure of one concept onto another. Discussions about disciplines are very often expressed using landscape metaphors-e.g. "What is your field?" The English term, "field" is derived from "feld" meaning open country. There is an expanding awareness of the value of interdisciplinary teams; at the same time, there is as well as growing scholarly literature describing the ongoing transformation of disciplinary structures of knowledge production. These changes are signaled by a growing list of prefixes: interdisciplinary, multidisciplinary, transdisciplinary, pre-disciplinary-, cross-disciplinary, anti-disciplinarity and post-disciplinary. In his discussion of "post-disciplinarity," Mario Biagioli has argued that the conceptual model of the organization of knowledge in the sciences is shifting-from "From Discipline and Canon to Collaborations and Problems"-in ways that scholars in other fields (there's that word) might find useful.[17] It is perhaps especially productive to use the Mental Landscape kit within a context where the landscape metaphor may no longer adequately express people's experience of what they know and how they work.

In the context of the Chicago workshop series explored in this paper, Mental Landscapes was used for the first session. We posed the following questions as prompts for participants: "How do we each imagine our knowledge in 
relation to other people's? What would our 'areas of expertise' look like if they were actual 'areas'? We asked participants, in groups, to choose elements and build models, on a black foam core surface, that responded to the questions. The suggestion was that participants might initially create their own 'parts' of the model, and then discuss how to build a landscape together from them, prompting discussion around the intersections and differences between people's areas of expertise and knowledge.

Some illustrative moments and vignettes from the group modeling include: 1) A group who found that the issue of the climate crisis was shaping their collective landscape, with its inevitable approach being modeled as something like a storm front, a bright red rectangle sweeping in, towards everything in its path; 2) A participant who showed his disciplinary training and expertise (in computer science) as being 'walled in', corralled behind a fence- he said he felt he could see other areas of interest outside, but felt unable to reach them; and 3), A group who used 'rivers' labeled "Why? What?" as a way to unite the different areas of knowledge they identified they had collectively, seeing the rivers as being something like a 'common thread' (to use another metaphor) of questioning running through their professional expertise (See Figures 3 and 4).

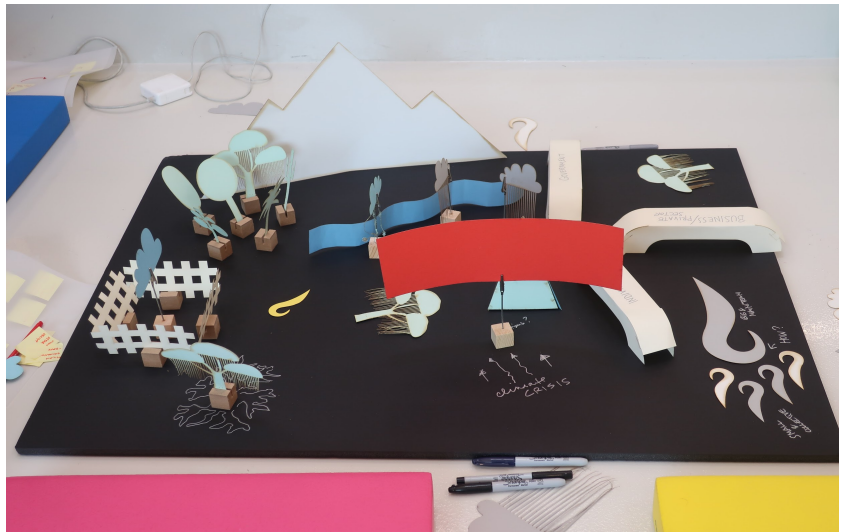

Figure 3. Both the climate crisis storm front and 'fenced in' area are visible here. Image: Dan Lockton.

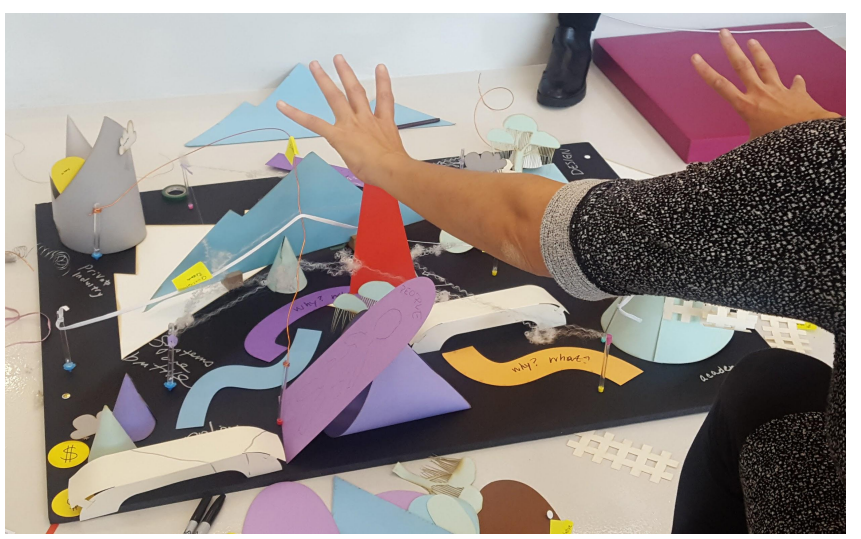

Figure 4. Rivers of "Why? What?" This photo (taken during the next stage of the workshop) also includes connective material elements. Image: Dan Lockton.
In each case here, the material properties, and specific affordances, of the elements (flexible, positionable, perforated, placeable in a meandering way) contributed to the kinds of sensemaking and storytelling that were possible. Deploying elements of landscape involves the arrangement of materials pre-figured into shapes and forms to reflect emerging sense-making. However, participants' use of, for example, rivers to link parts of the landscape together suggests a need unmet by a static set of elements: it is perhaps these connections between ideas and concepts, and the nature of those links, that prompt a different narrative.

\subsection{Emphasizing connective tissue}

The next stage of the workshop process was based on methods arising from Aguirre Ulloa and Paulsen.[18] Participants were asked to augment their landscape models using materials that emphasize connections and relations (elements of this second workshop overlay are visible in Figure 4). Participants were asked: How are the different areas of knowledge related? What relationships influence our fields of practice? What do these relationships look like? What are their qualities, properties, values and "materials"? Workshop materials included copper wire, elastic thread, yarn, and elastic banding (Figure 5). Their variegated material qualities-thick, rough, smooth, stretchy, shiny, elastic, fragile-were intended to help participants focus especially on the character of "in-between" — and to co-construct physical forms that conveyed the nature of social and epistemological relationships that characterize their experiences of interdisciplinarity.

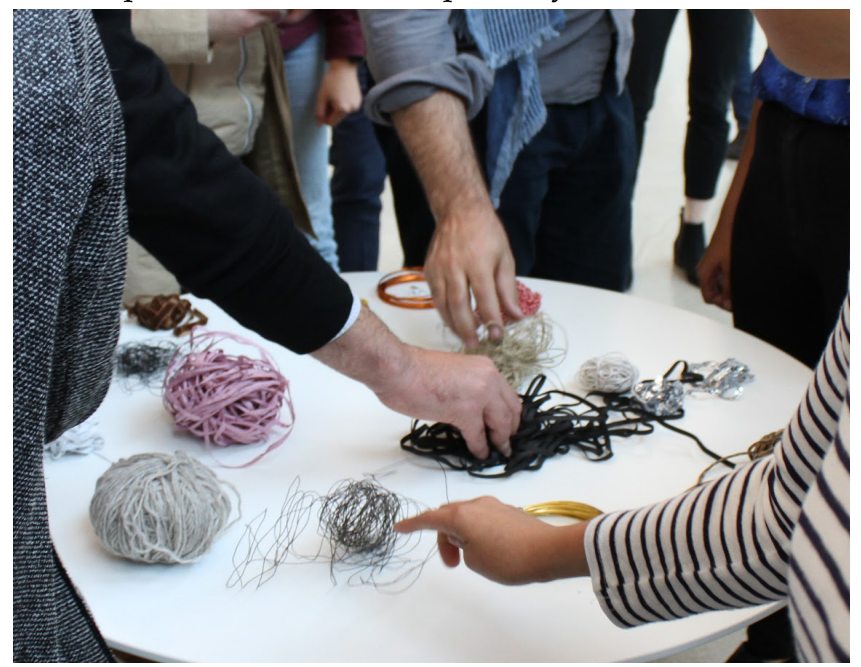

Figure 5. Supply of connective materials emphasizing differing qualities of relation: elastic, shiny, rigid, lose, firm, fuzzy. Image [not sure].

The workshop's connective materials did indeed provoke just this sort of conversation about cross-disciplinary and interdisciplinary work. For example, one participant working in a group of five chose a short strand of silver sequence from the pile of materials at the front of the room. She described her choice to her group members, explaining that working in a way that connects two different disciplines can seem very appealing from the outside, like a shiny thing: "I chose this [strand of silver sequence] 
because, in many cases, the connection between two different disciplines seems...well, everyone says, 'oh! that's cool, that's great, you're working in sociology and design!'" Then she knotted the strand to make her more emphatic point: trying to forge a career by working across disciplines can be very difficult: "But then-and you know, and this is a very personal thing-for my career, it's not cool. So it's like shiny and nice, but then..." And, here another member of the group completed her sentence, adding to the building narrative "-and then there's the reality." The first participant began to drape her shiny strand from one paper cone (taken to represent a discipline) to another paper cone (Figure 6). At this point, another participant adds, "But maybe the shiny thing is not the connector piece." And, another still, "Yes, maybe put it around here, yeah, I'm not sure if it is a connector." (Figure 7). The group was collectively building a narrative about the paradoxical character of interdisciplinary work.

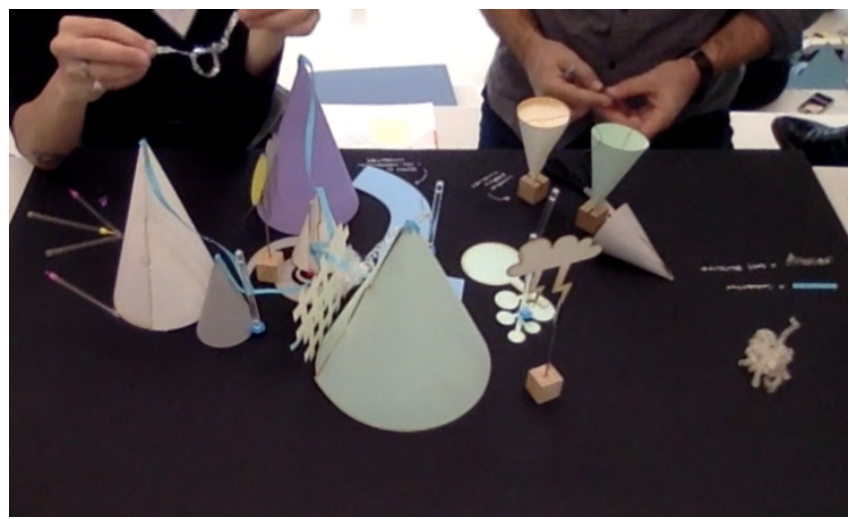

Figure 6. A knotted strand of silver sequins used to convey the appeal and also the difficulty of interdisciplinary work/working across disciplines. Image: Lisa Brawley (video still).

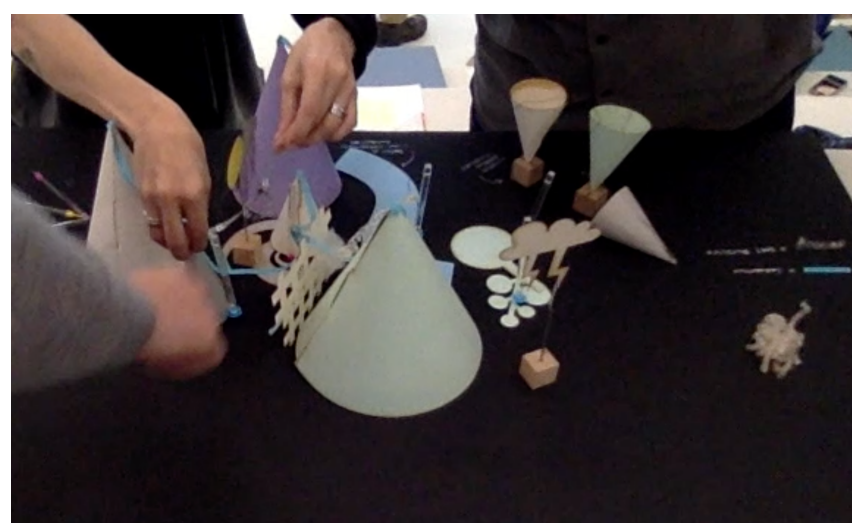

Figure 7. Participants discuss where to place the shiney strand of silver. Image: Lisa Brawley (video still)

\subsection{Exploring dynamic performance}

The third session of the workshop introduced the notion of time. In this session participants created new models rather than augmenting the model they had created in the first two sessions by deploying elements of landscape and emphasizing connective relationships. The materials used had varying temporal qualities: they are expressed or materialized in time: rolling, dissolving, dripping, magnifying, and flashing on and off. The materials included glass marbles, wooden chutes, LED lights, a magnifying lens, ink, and sugar cubes. These materials were intended to encourage/allow participants to express temporal experience and the dynamic nature of ideas; these materials facilitated the performance of dynamic change: knowledge systems change, knowing takes time. A second performative aspect came in here when participants altered and re-arranged the materials in a live explanation of what they did. Instructions to participants did not narrowly specify what to do but rather materials are presented, a theme is proposed and a duration is given. People were free to organize, classify and align these materials in ways that best suit the moment. This ambiguity helps to mediate the binaries experienced in spoken language and provokes modes of material engagement that allow people to discover unexpected connections.

One group brought these materials into a meaningful gestalt that expresses the dynamic and shifting nature of interdisciplinary relationships between technology, academia, science, policy, and design (Figure 8). This group sought to capture 'the tension and influence between arts and everything else' by showing in two and three dimensions how elements of the chosen dispositif are related. Attention, which they explained was represented by the marble in a wooden chute, is shown moving from technology towards art and design, whilst attention in academia increasingly turns towards critiques of technology. Using the lights allowed the group to show how attention turns gradually towards effects of system interactions-it is not a sudden realization but a sense of growing awareness.

The specific focus for another group's physicalization was the growing influence of business on government policy. This was shown by the use of lenses which moved in and out (in the live explanation of the model) that enable 'looking in' and 'zooming in'. This happened at different speeds and at different levels of magnification for the various aspects of the system. Red ink, standing for human blood, was dripped onto the sugar cubes, demonstrating the potential cost in human lives of policies overly influenced by business objectives. Again the progressive, gradual absorption by the sugar cubes of the ink stands for a dawning realization rather than immediate understanding. Relationships are shown using curling lines drawn onto the base paper layer to indicate that interdisciplinary relationships are not linear or static; 'the messy relationship that connects all these different fields together is human behavior'.

The materials were chosen by the group so as to allow for contrasting and complementary representations (Figure 9). So the steady, unblinking nature of an LED light illuminates a specific area of the model and is small enough to be limited in what it can highlight, but can also fit inside one of the wooden cubes. Sugar cubes can be stacked or lined up, cultured ink diffuses slowly through them onto the paper below, but must be carefully dripped onto them requiring deliberation and a steady hand. The glass marbles run through the wooden chutes much faster and are here used as connective devices to help explain how attention shifts between knowledge domains. Lenses sit on the 
base paper magnifying a specific area. When the group explained what they had done and why, they picked up these lenses and moved them slowly from arms length away to directly above a confluence of the orange and green lines drawn in tape on the base paper.

The collaborative and participatory nature of the modeling exercise means that materials were able to work in a variety of ways. Group members used the physical materials to express various aspects of the system, such as gradual state change, the placing of awareness, and shifting attention. The materials were selected by the group for their relative sizes. Objects are arranged in a way that communicates at a coherent scale, no one material dominates the model. The contrasting speeds of change have been carefully arranged; the fast run of a marble through a chute, the slow absorption of liquid by a sugar cube, a human controlled zoom in with a lens. The characteristics of the individual materials allow the group members to collectively and consensually assign them a particular metaphorical function that is played out in the model.

What is being expressed in this physicalization is a group understanding of how elements of a gradually changing situation are related to one another. Using physical materials means making choices about what the right materials are and what the most effective arrangement is. Using materials that change shape, position, intensity, and distance complicates things by rendering the whole physicalization unstable. The data being physicalized here are differing internal attitudes and opinions about a set of interdisciplinary relationships, a highly abstract subject difficult to express in spoken or written words. The physical and spatial qualities of the representation allow for everything to be said at once. The situation, a generative co-design workshop, affords a group telling of the physicalization, transforming it into a time-based narrative object.

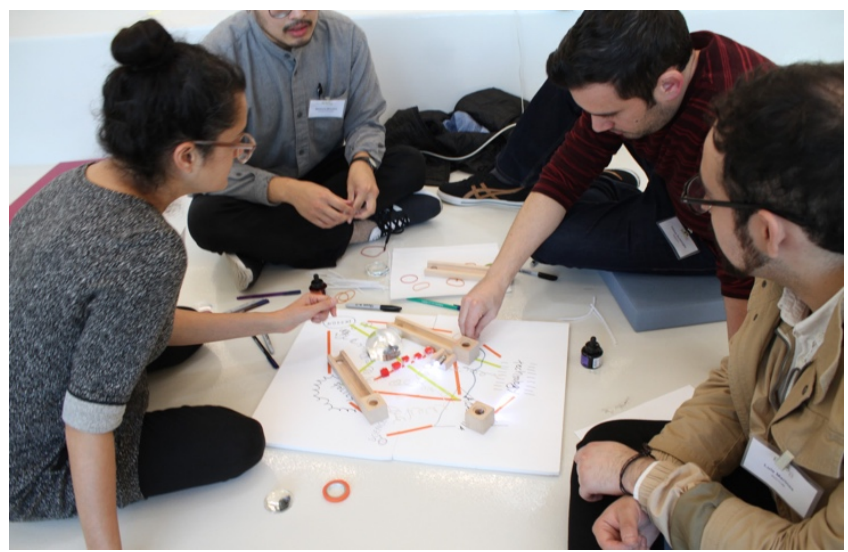

Figure 8. Participants organized materials to show their interrelationships. Image: John Fass.

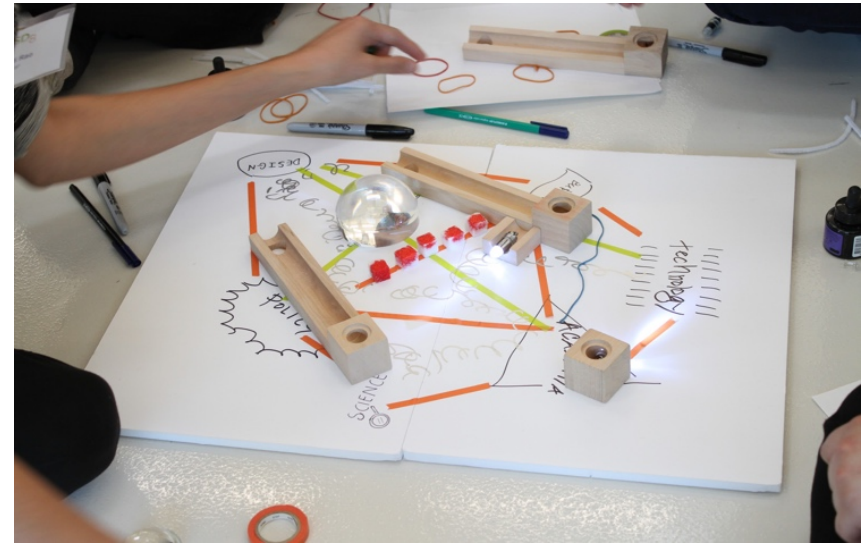

Figure 9. This image shows participants arranging the elements to show how the attention is shifting over time from technology towards art and design. Image: John Fass.

In the second example from the same session, two participants chose the following rather unlikely selection of materials: a marble, photo sensitive paper, orange water soluble ink, a segment of wooden track, a magnifying lens, and an LED light (Figure 10). They together began to play with these materials - or to see how much play the materials afforded. The diverse properties of these materials seemed to invite this sort of unscripted exploration: the team dropped the marble, then dipped it in ink and dropped it again, and watched the path it traced across the paper. They were discovering, and discovering together, what the materials would do and what they could do with them. They were not only learning about what each would do with the materials, but also learning about each other in this way (Figure 11). One participant explained, "We had no idea what these would do, or what we would do with them; we had to begin in order to discover that."' One participant suggested the process itself demonstrated the temporal dimensions of working with complexities such as areas of expertise that shift overtime.

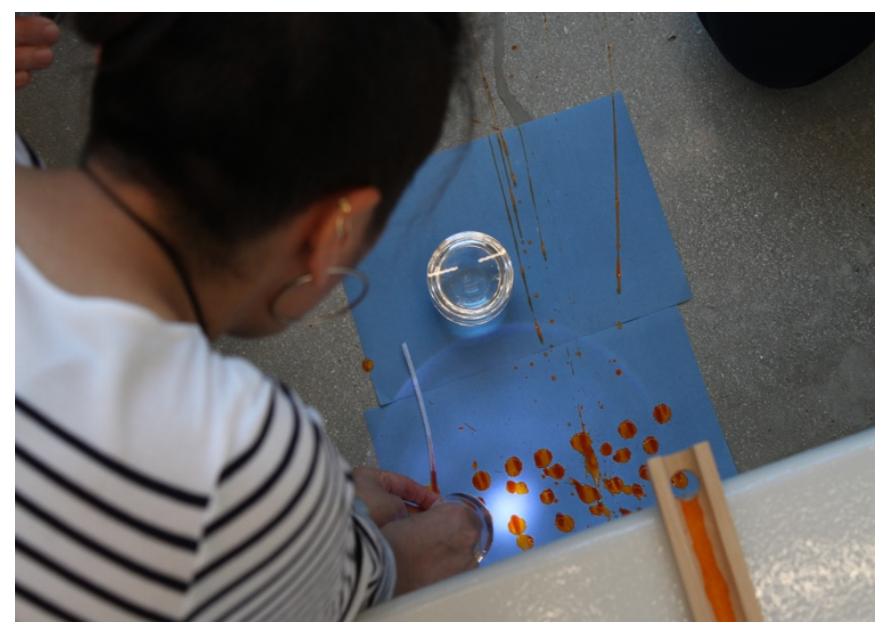

Figure 10. Drip, splat, roll: photo sensitive paper, orange water soluble ink, a segment of wooden track, a magnifying lens, and an LED light. Image: John Fass. 


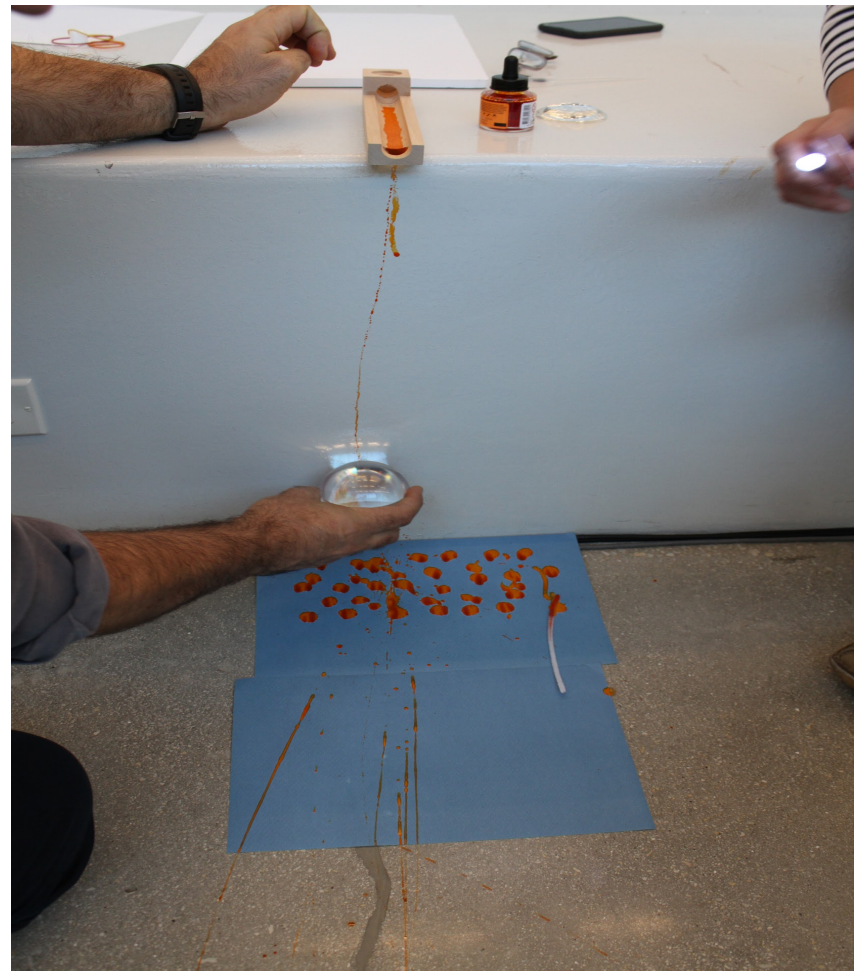

Figure 11. Participants exploring together the capacities of the varied materials they chose. Image: John Fass.

\section{Discussion: What's the USE? AMBiguity, PHYSICALIZATION AND SHARED NARRATIVE}

Across the three sessions of the workshop, multi-valent materials both enticed and enabled members of co-design groups to develop a shared narrative about their understanding of and experience with, in this case, cross-disciplinary work; the differing qualities of varied materials became prompts and props for storytelling-their differing materials often calling out different kinds of stories. In addition, the modeling process-making, arranging, discussing, negotiating, telling, proposing, placing, connecting, doing-allowed for more than representing, externalizing or expressing. Instead, we argue that there is a deepening of mutual understanding through shared discovery. Participants act with materials in a way provoked both by their physical properties and by their dynamic connection. Different kinds of materials arranged in temporal relation and experienced in shared encounter elicit richer and more richly shared understandings than straightforward representations. As a result, we find ourselves designing not so much physical tools for representation as material situations where the work of developing shared understanding is made perceivable.

In all these examples, participants are not simply externalizing interior concepts and feelings they hold as individuals, but in interacting with the tangible materials and with other members of their group, they are developing ideas and building a model that both supports and reflects elements of the narrative they are creating together. What results is not a model (or data physicalization) in a typical sense. Rather it is a material trace, tangible evidence left behind of the conversation the group had. One question we are left with is what is the nature of the model created by these traces of shared use? They "are not stable artifacts whose correct interpretation is just a matter of visual literacy, but phenomena that emerge from a recipients' extensive engagement with the world and with the knowledge of others" In this key sense, the structures that the groups created are analogous to "autographic visualizations" created by "material traces" of a shared encounter.[19]

As Sara Ahmed reminds "'usefulness' is not merely instrumental but is about capacities that are open to the future. The capacity is not so much 'in' the tool [or in this case, in the workshop materials we provided] but depends upon how the tool is taken up or 'put to use'[20]. Thus, another question might be what kinds of tangible materials and combination of materials leave them powerfully "open to the future" - which is to say inviting, enticing, or otherwise readily available to be used by participants as they craft shared understandings. Coming to a shared understanding takes work but this work is often invisible and intangible. Here, by asking participants to use these diverse physical materials to create models of interdisciplinarity, we were also asking them to make visible- to leave a trace of - the effort required to understand each other's point of view.

An important aspect of how materials were chosen for this workshop is that their usefulness was ambiguous: unlike a pile of post-it, there was no set or pre-ordained way to use these tangible materials. In addition, the workshop materials emphasized increasing degrees of ambiguity across the three sessions-from landscape elements that might more readily suggest a "field," to connective tissue that lend themselves to thinking of the "inter" of "interdisciplinarity, to varied time-expressing materials (a marble, a sugar cube, light sensitive paper) that more fully thwart the guiding landscape metaphor that often anchors conversations about disciplinarity. One question we could ask is whether the increasing ambiguity led people to discover more nuanced aspects of how disciplinarity and interdisciplinarity come to have meaning for them.

\section{Conclusion}

We used three modes-deploying elements of landscape, emphasizing connective tissue, and exploring dynamic performance- to elucidate and physicalize complex qualitative data. The work we have done can be seen as an expansion of the affordances and possibilities of the field of data physicalization. We have taken data to stand for the qualitative nature of lived experience as discoverable through the actions of making and talking about making, a physical representation. We are concerned with the physical properties of the materials that allow this to happen, but are increasingly alert to the emergent social circumstances that arise when doing so in a collaborative shared situation. We draw on notions of post-critical materiality and the types of knowledge generated in practice-based design research to position our work as intrigued by the 
interplay of artifact and person, relations and telling, material and time.

In the examples that we have discussed the topic was interdisciplinarity, how people understand their ways of knowing and working. Our approach deployed ambiguity to the extent that not assigning narrowly specific meanings to materials, connections and movements bur rather leaving these "open to the future" - enables and requires participants to posit meanings for themselves-to develop shared narratives of what individual elements mean and what they their arrangement in time and space implies about the questions they are answering together. A shared expression of the relations between materials, contextualized by the modes we have described, often results in a shared telling of the exercise with participants taking turns to explain the particular meanings they have imparted to the materials.

There is a politics of materials that is also important here: where people might have seen or used them before, how they may trigger associations from childhood play, office life, or craft making, and how they may not be readily associated with design activity. A politics of materials also extends to the processes that make them available to us to use as the "raw materials" of a co-design workshop. These aspects of thinking tangibly are beyond the specific scope of this paper.

The type of knowledge generated through this kind of co-created, shared encounter with ambiguous physical materials is discursive, contingent and sometimes unanticipated. It is characterized by serendipitous discovery and an uncovering of unseen connections. In this way, we see this work as more than extractive. That is, it goes beyond externalizing thoughts, opinions or attitudes that are internal. The properties and characteristics of objects and the relationship between them act as mediating agents not only for how peoples' mental models and lived experiences structure their understanding of the world around them, but for an opening towards new shared realizations and deepened understanding - not just for surfacing but also for generating new forms of knowledge.

\section{ACKNOWLEDGMENT}

This paper examines a workshop we convened at RSD8: Relating Systems Thinking and Design Symposium, 17-19 October 2019, Chicago: "Tangible Thinking: Materializing how we imagine and understand interdisciplinary systems, experiences, and relationships." The conference proceedings include a more extensive set of references and examples than we could include here.

We especially thank Manuela Aguirre Ulloa (Designit \& Oslo School of Architecture and Design), for co-designing and leading the second session, which is based in her doctoral research. She was unable to join as a co-author of this essay because she was completing her dissertation.

From Carnegie Mellon, we also thank Matt Prindible for crucial support in preparing for and documenting the workshop, Katie Herzog for insights around materials and form arising from her Emotional Modeling project, Tammar Zea-Wolfson for additions to the Mental Landscapes kit, and Delanie Ricketts for originating the kit. We also thank Karianne Rygh and Palak Dudani (Oslo School of Architecture and Design) for insightful input and feedback on the workshop design and during the workshop discussion.

Corresponding author John Fass: E-mail: j.fass@arts.ac.uk. 


\section{REFERENCES}

[1] Tversky, B. 2015. The Cognitive Design of Tools of Thought. Review of Philosophy and Psychology 6, 99-116. https: / / doi.org/10.1007/s13164-014-0214-3. P. 99

[2] Kirsh, D., 2010. Thinking with external representations. AI \& society, 25(4), 441-454; p. 448.

[3] H.-J. Rheinberger, Toward a History of Epistemic Things: Synthesizing Proteins in the Test Tube. Stanford, CA: Stanford University Press, 1997.B. Ewenstein and J. Whyte, "Knowledge Practices in Design: The Role of Visual Representations as 'Epistemic Objects'," Organization Studies, vol. 30, no. 1, pp. 7-30, 2009.

[4] K. Henderson, "Flexible Sketches and Inflexible Data Bases: Visual Communication, Conscription Devices, and Boundary Objects in Design Engineering," Science Technology \& Human Values, vol. 16, no. 4, pp. 448-473, 1991

[5] S. L. Star and J. R. Griesemer, "Institutional ecology,translations' and boundary objects: Amateurs and professionals in Berkeley's Museum of Vertebrate Zoology, 1907-39," Social studies of science, vol. 19, no. 3, pp. 387-420, 1989.

[6] P. Galison, "Trading with the Enemy," in Trading Zones and Interactional Expertise: Creating New Kinds of Collaboration, M. E. Gorman Ed. Cambridge, MA: MIT Press, 2010, pp. 25-52.

[7] C. Lury and N. Wakeford, Inventive Methods: The happening of the social. New York, NY: Routledge, 2012.

[8] Candy, L., 2006. Practice based research: A guide. CCS report, 1, pp.1-19. Zeisel, J., 2006. Inquiry by design. Environment/behavior/neuroscience in architecture, interiors, landscape, and planning. McCormack, D.P., 2008. Thinking-spaces for research-creation. Inflexions, 1(1), pp.116. Sanders, Liz, and Pieter Jan Stappers. Convivial Design Toolbox: Generative Research for the Front End of Design. BIS, 2012.

[9] J. Sayers, Making Things and Drawing Boundaries: Experiments in the Digital Humanities. University of Minnesota Press, 2018.

[10] M. Ratto, "Critical making: Conceptual and material studies in technology and social life," The Information Society, vol. 27, no. 4, pp. 252-260, 2011.

[11] M. Halpern, I. Erickson, L. Forlano, and G. Gay, “Designing Collaboration: Comparing Cases Exploring Cultural Probes as BoundaryNegotiating Objects," in Computer Supported Collaborative Work, San Antonio, TX, 2013.

[12] R. Wakkary, W. Odom, S. Hauser, G. Hertz, and H. Lin, “Material speculation: Actual artifacts for critical inquiry," in Proceedings of The Fifth Decennial Aarhus Conference on Critical Alternatives, 2015: Aarhus University Press, pp. 97-108.

[13] Boer, L. and Donovan, J., 2012, June. Provotypes for participatory innovation. In Proceedings of the designing interactive systems conference (pp. 388-397).

[14] D. J. Haraway, "SF: Science Fiction, Speculative Fabulation, String Figures, So Far," ADA: A Journal of Gender New Media \& Technology, no. 3, 2011. [Online]. Available: http://adanewmedia.org/2013/11/issue3-haraway/.

[15] Ricketts, D. and Lockton, D., 2019. Mental landscapes: externalizing mental models through metaphors. interactions, 26(2), pp.86-90. [16] Jonassen, D. and Cho, Y.H., 2008. Externalizing mental models with mindtools. In Understanding models for learning and instruction (pp. 145-159). Springer, Boston, MA.

[17] Biagioli, Mario. "Postdisciplinary Liaisons: Science Studies and the Humanities." Critical Inquiry 35, no. 4 (2009): 816-33. Accessed February 5, 2020, p. 818. doi:10.1086/599586.

[18] Aguirre-Ulloa, M., \& Paulsen, A. (2017). Co-designing with relationships in mind. FormAkademisk - forskningstidsskrift for design og designdidaktikk, 10 (1). https: / doi.org/10.7577 / formakademisk.1608

[19] Offenhuber, D., 2019. Data by Proxy-Material Traces as Autographic Visualizations. IEEE transactions on visualization and computer graphics, 26(1), pp.98-108.

[20] Ahmed, S., 2006. Queer Phenomenology: Orientations, Objects, Others. Duke University Press.
$+++$

Dan Lockton holds a BSc Industrial Design Engineering from Brunel University (2004); an MPhil in Technology Policy from the University of Cambridge (2005); and a PhD in Design from Brunel (2013). After working in the design industry, Dan was a research assistant at Brunel University, research fellow at the University of Warwick, senior research associate at the Royal College of Art's Helen Hamlyn Centre for Design, and research tutor in Innovation Design Engineering at the Royal College of Art, before joining Carnegie Mellon University in 2016 as an assistant professor. He established the Imaginaries Lab at Carnegie Mellon, a new design research studio. Dan is involved with a number of ACM conferences including CHI, DIS, and C\&C (Creativity and Cognition), along with design conferences including DRS and EPIC. His research interests are centered on the use of design methods to investigate people's understanding of the world, and help people imagine new ways of living and understanding, to enable more environmentally and socially sustainable futures.

Laura Forlano holds a BA. in Asian Studies from Skidmore College (1995); a Diploma in International Relations from The Johns Hopkins University (2000); an MIA. in International Affairs from Columbia University (2001); and, a PhD. in Communications from Columbia University (2008). After completing Postdoctoral Associate positions at Yale University and Cornell University, she has been faculty at Institute of Design at Illinois Institute of Technology since 2011 where she is currently Associate Professor of Design and Director of the Critical Futures Lab. Forlano is a member of the Society for the Social Studies of Science (4S), the International Communication Association and the Design Research Society (DRS). She is an editor of three books: Bauhaus Futures (MIT Press 2019), digitalSTS (Princeton University Press 2019) and From Social Butterfly to Engaged Citizen (MIT Press 2011). Forlano's research is focused on the aesthetics and politics at the intersection between design and emerging technologies.

John Fass holds a B.A. in Photography, Film, Video, \& Animation (1992), an MRes in Information Environments (2011), and a PhD Communi-cation Design (2018). He is currently course leader for MA User Experience Design at London College of Communication, and runs De-computation, an elective in Information Experience Design at the Royal College of Art. He sits on the Program Committee for Research Through Design and received doctoral funding from the AHRC followed by a Post Doctoral Fellowship award. His current research in-terests include methods of externalisation, post humanist design methods, and interface ethics. He is a member of the Design Research Society and IxDA.

Lisa Brawley Lisa Brawley holds a BA in studio art and feminist theory from the Center for Interdisciplinary Studies at Davidson College (1982); an MA in Performance Studies from New York University (1986); and a $\mathrm{PhD}$ in American Studies from the Committee on Ideas and Methods at the University of Chicago (1995). She received doctoral funding from the Whiting Foundation. She taught American Studies at Loyola University Chicago and Kent State University before joining the Urban Studies and American Studies Programs at Vassar Col-lege in 2000. She is Director-elect of the Urban Studies Program, fol-lowing a three-year appointment as the Anne McNiff Tatlock Chair of Multidisciplinary Studies. She is coauthor of a bilingual book on urban design and agricultural modernity, D'après nature: Frederick Law Olmsted et le Park movement américain (2014). She edited Postmod-ern Culture for nine years and now serves on its advisory board. She serves on the Scientific Board of the journal Justice Spatiale/Spatiale Justice. Her research addresses cultural histories of capitalist urbanization in the U.S. with a current focus on participatory design methods, feminist spatial practices, and the just transition movement. She is a member of the Design Research Society and the American Studies Association. 